\title{
Guidelines for the treatment of lung cancer using radiotherapy
}

\section{DIRETRIZES PARA TRATAMENTO DE CÂNCER DE PULMÃO COM RADIOTERAPIA}

\author{
Authorship: Brazilian Society of Radiotherapy (SBR) \\ Participants: Michael J. Chen ${ }^{1}$, Paulo Eduardo Novaes ${ }^{1}$, Rafael Gadia ${ }^{1}$, Rodrigo Motta $^{1}$
}

Final draft: August 2017

${ }^{1}$ Sociedade Brasileira de Radioterapia (SBR)

The Guidelines Project, an initiative of the Brazilian Medical Association, aims to combine information from the medical field in order to standardize procedures to assist the reasoning and decision-making of doctors.

The information provided through this project must be assessed and criticized by the physician responsible for the conduct that will be adopted, depending on the conditions and the clinical status of each patient.

\section{Grades OF RECOMMENDATION AND LEVELS OF EVIDENCE}

- A: Experimental or observational studies of higher consistency.

- B: Experimental or observational studies of lower consistency.

- C: Cases reports (non-controlled studies).

- D: Opinion without critical evaluation, based on consensus, physiological studies or animal models.

\section{Objective}

The aim of this guideline is to evaluate the most appropriate radiotherapy technique to treat patients with lung cancer.

\section{Description OF EVIDENCE COLLECTION METHOd}

Through the elaboration of four relevant clinical questions related to the proposed theme, we sought to present the main evidences regarding safety, toxicity and effectiveness of the presented radiotherapy techniques. The study population consisted of male and female patients of all ages with lung cancer, regardless of histological type, staging or presence of comorbidities. For this, a systematic review of the literature was carried out in primary scientific databases (Medline - PubMed; Embase - Elsevier; Lilacs - Bireme; Cochrane Library - Record of Controlled Trials). All articles available through April 31, 2015 were considered. The search terms used in the research were: ((lung cancer) OR (lung carcinoma)) AND (IMRT OR intensity modulation OR intensity modulated) AND (conventional OR 2D OR two dimensional OR bidimensional OR standard OR conformal OR 3D OR tridimensional OR CRT OR three dimensional). The articles were selected based on critical evaluation using the instruments (scores) proposed by Jadad and Oxford. The references with greater degree of evidence were used. The recommendations were elaborated from discussions held with a drafting group composed of four members of the Brazilian Society of Radiotherapy. The guideline was reviewed by an independent group, which specializes in evidence-based clinical guidelines. After completion, the guideline was released for public consultation for 15 days, and the suggestions obtained were forwarded to the authors for evaluation and possible insertion in the final text.

\section{INTRODUCTION}

Radiotherapy is an integral part of the multidisciplinary treatment of lung cancer.

In small cell lung cancer, radiotherapy is performed after chemotherapy (adjuvant) in tumors staged as extensive disease, ${ }^{1}$ and concomitantly in tumors staged as localized disease. ${ }^{2}$

In non-small cell lung cancer, radiotherapy is indicated before or after surgery (adjuvant), with the purpose of making them surgically resectable or to prevent relapse of locoregional disease and tumors with positive margins, ${ }^{3,4}$ while in unresectable tumors, it is preferably associated with chemotherapy. ${ }^{5}$

Radiation therapy has progressed in recent decades due to advances in computerized systems that allow the recognition of internal structures in the body. This recognition is done based on the patient's imaging investigation, usually computed tomography. A more accurate dose distribution that reaches the area intended to be treated while sparing normal organs derives from the information sent to the radiation device from a previously configured treatment planning system. This release 
dosage form is known as conformal technique. The software shows the radiation dose distribution inside the patient's body and creates dose-intensity graphs on each target organ or volume. It is thus possible to know the potential toxicity of these organs and whether the tumor is being adequately treated. ${ }^{6}$

Even though the conformal technique allows for dose assessment at irradiated site, sparing healthy organs, it does not provide ways of protecting tissues in close contact with irradiation treatment targets. The intensitymodulated radiation beam technique was developed to solve this problem. It allows the prescribed dose to "fit" within the contour of the site to be irradiated, allowing maximum protection of areas not intended for treatment.

In the thoracic region, which houses several radiationsensitive organs, such as the heart, esophagus, spinal cord, and lungs, conformal radiotherapy is the minimally recommended technique for patient safety. ${ }^{6}$

Based on clinical experience with complications of radiotherapy, a dose-limiting standard according to the volume of a normal organ was created and published in 2010, the Quantitative Analysis of Normal Tissue Effects in the Clinic (Quantec). ${ }^{7}$ The recommendation was developed by the joint work of several researchers, authors, reviewers and support professionals. It is currently recommended throughout the world as a practical guide to performing radiotherapy on all parts of the body. Such dose quantification can only be established from the shaped technique.

For the reasons given above, conventional radiotherapy has been abandoned whenever the treatment site is close to radiation-sensitive organs (for example, the chest), since this technique does not provide any information on dose distribution in these organs. In this case, both the locoregional control of the disease is dose-dependent and appears to be directly related to survival, ${ }^{8}$ and residual lung function after treatment seems to be an important factor related to quality of life in survivors. ${ }^{9}$

\section{IS THERE SUPERIORITY IN DOSE DISTRIBUTION FOR IRRADIATION OF LUNG CANCER WITH INTENSITY MODULATED RADIATION THERAPY (IMRT) COMPARED TO CONFORMAL RADIOTHERAPY?}

There are no prospective phase III studies comparing conformal radiation therapy and IMRT for any chest cancer. Therefore, other factors should be weighed and considered to choose the best radiotherapy technique. These factors include, for example: dosimetric advantage, technology accessibility, financial aspects, and decision to escalate the dose or maintain the restriction of doses released on a critical organ. ${ }^{10}$
IMRT can improve the physical and biological conformability of the dose and enable its scaling within the target volume, which makes it possible to release higher doses to target subvolumes such as the hypoxic areas or those capturing high SUV on PET-CT, with no need to increase the number of fractions, and maintaining a low dose exposure to healthy tissues. ${ }^{11}$

Virtual simulation studies have shown that IMRT may be more appropriate than conformal radiotherapy for patients with large tumor volumes and difficult position within the thoracic anatomy, cases in which protection of normal surrounding structures is a priority. These studies presented a $7 \%$ reduction in the irradiated lung volume with more than $10 \mathrm{~Gy}$, and $10 \%$ with more than $20 \mathrm{~Gy}$. Volumes of heart and esophagus irradiated with up to 50 Gy, as well as volumes of lung tissue irradiated between 10 and $40 \mathrm{~Gy}$, were also reduced with IMRT compared to conformal radiotherapy. ${ }^{12}(\mathrm{D})$

For bronchial neoplasms close to critical organs (esophagus, heart, brachial plexus), IMRT may have dosimetric advantages compared to 3 DCRT. ${ }^{10}(\mathrm{D})$

Other points to consider include: IMRT can release greater low dose volumes in areas of healthy lung, it may result in failures outside the therapeutic margin leading to differences in sterilization of lymph nodes incidentally not included in the target volume, and the lower dose rate may be less lethal for neoplastic cells. ${ }^{13}$

\section{IS THERE LESS TOXICITY IN THE USE OF IMRT IN RELATION TO CONFORMAL RADIOTHERAPY FOR LUNG CANCER?}

Toxicity related to radiotherapy external to primary lung tumors can be temporally divided into acute or late. Anatomically, it is divided into pulmonary and esophageal, because these are the main organs to manifest adverse reactions to radiation.

Comparing IMRT with conformal radiotherapy of lung tumors, two studies had as their main toxicity outcome, i.e., pulmonary toxicity:

1. A retrospective study of 290 patients showed that at month 6 , treatment-related grade $\geq 3$ pneumonitis rates reached 8\% (95CI 4-19\%) with IMRT and 22\% (95CI 17-29\%) with conformal radiation therapy. At month 12 , treatment-related grade $\geq 3$ pneumonitis rates reached 8\% (95CI 4-19\%) with IMRT and 32\% (95CI 26-40\%) with conformal radiation therapy $(\mathrm{p}=0.002) .{ }^{14}$ (B)

2. Another retrospective study with 409 patients being treated reported a significant difference $(\mathrm{p}=0.017)$, both 6 and 12 months after radiation, in favor of IMRT 
with $90 \%$ of patients without treatment-related pneumonitis, versus conformal radiotherapy, with $75 \%$ free of this toxicity. ${ }^{15}(\mathrm{~B})$

Toxicity to normal tissue is the major obstacle to be dodged in order to make it possible to release a suitable dose, aiming at better tumor control. One of the tissues most sensitive to radiation is the lung. Depending on the lung volume receiving a given dose, as well as other factors (pulmonary reserve, radiobiological factors, concomitant therapy), patients may not present with acute symptoms, but only asymptomatic pulmonary fibrosis evidenced in the radiation field (typically 12 months or longer after treatment), transient moderate pneumonitis (typically 2-6 months after radiotherapy), or a more symptomatic, severe, or even fatal disease. Thus, volumetric parameters such as V20 (percentage of pulmonary volume receiving $\geq 20 \mathrm{~Gy}$ ), V10 and V5, and pulmonary mean dose have been shown to be the most important predictive factors for severe pulmonary toxicity. ${ }^{14,16-18}$

The lung is the thoracic organ most sensitive to the deleterious effects of radiation, but this does not mean that it is the only limiting anatomical structure to restrict the appropriate dose release. Spinal cord, esophagus, and heart are also restrictive. The spinal cord, for example, should be protected from doses > $45 \mathrm{~Gy}$.

The esophagus does not have a critical dose limit such as the spinal cord, but acute damage caused by radiation can be identified even at modest doses depending on the volume irradiated. Significant esophageal morbidity is routinely reported, which often limits the administration of an appropriate treatment, using optimal dose and without interruptions, especially if concomitant with chemotherapy and/or whenever mediastinal lymph nodes should be addressed. ${ }^{19,20}$

A recently published retrospective study with 223 patients showed that the rate of patients with severe esophagitis requiring feeding tube was $5 \%$ with IMRT versus $17 \%$ with conformal radiotherapy $(\mathrm{p}=0.005) .{ }^{11}(\mathrm{~B})$

\section{IS THERE AN IMPACT ON QUALITY OF LIFE THAT JUSTIFIES THE USE OF IMRT COMPARED TO CONVENTIONAL AND CONFORMAL RADIOTHERAPY?}

One of the goals when we offer a modality of treatment for any type of cancer is the preservation or improvement of the patients' quality of life. However, because it is an outcome that is difficult to assess due to both subjectivity and the scarcity of objective tools for its measurement, there is little information on the subject.

The best study that evaluated the impact on quality of life of lung cancer patients treated with different ra- diotherapy techniques was published as a summary, not providing the full text. This was a randomized clinical trial whose main objective was to evaluate the impact of treatment on the survival of patients with locally advanced lung cancer after high-dose radiotherapy (60 Gy x 74 Gy). As a secondary outcome, information regarding quality of life was prospectively collected using instruments validated for patients with lung cancer, and the following results were found: ${ }^{21}(\mathrm{~A})$

1. Of the 419 patients included in the study, $45 \%$ underwent IMRT and 55\% underwent conformal radiotherapy. The two groups were equally distributed in terms of patient characteristics, except for tumor size that tended to be larger in the IMRT group.

2. In all, 357 patients completed the questionnaires to assess quality of life before treatment. The questionnaires used were as follows: "Functional Assessment of Cancer Therapy-Trial Outcome Index" (FACT-TOI), "Physical Well Being" (PWB), "Functional Well Being" (FWB) and "Lung Cancer Subscale" (LCS).

3. Twelve (12) months after the end of treatment, patients who underwent IMRT presented better quality of life than those treated with conformal radiotherapy, according to all of the questionnaires evaluated. All differences were statistically significant.

\section{Is THERE A DIFFERENCE IN EFFECTIVENESS, LOCAL CONTROL OR OVERALL SURVIVAL BETWEEN IMRT, CONFORMAL AND CONVENTIONAL RADIOTHERAPY?}

Based on a comparison between IMRT and conformal radiotherapy for lung tumors, two studies evaluated disease control and survival outcomes:

1. A retrospective study included 223 patients with small cell lung cancer and evaluated two consecutive historical cohorts. The authors found no difference in local control, locoregional control, incidence of distant metastases, disease-free survival, and overall survival for patients undergoing chemotherapy and IMRT compared with conformal radiation therapy. ${ }^{11}(\mathrm{~B})$

2. Another retrospective study included 496 patients with non-small cell lung cancer and assessed two consecutive historical cohorts. The authors found better overall survival for patients undergoing concomitant chemotherapy and IMRT compared with conformal radiation therapy. In this study, median survival was $16.8 \pm 16.3$ months with IMRT and $10.2 \pm 6.4$ months with conformal radiotherapy (hazard ratio $=0.64[0.41$ 0.98], $\mathrm{p}=0.039) .{ }^{15}(\mathrm{~B})$ 
A retrospective study conducted from multi-institutional databases also evaluated the role of radiotherapy techniques in patient survival, demonstrating the superiority of IMRT or conformal techniques compared to the conventional technique, with 5-year survival rates of $14 \%$ for IMRT or conformal radiotherapy compared with $11 \%$ for conventional radiotherapy $(\mathrm{p}=0.0001)$. Another similar study demonstrated a better overall survival in the comparison between the IMRT or conformal radiotherapy techniques and the conventional technique, but did not demonstrate superiority of IMRT over conformal radiotherapy in terms of survival. ${ }^{22,23}$ (B)

\section{Conclusion}

Treatment with IMRT can provide more conformality and protect more critical structures than conformal radiotherapy, also allowing the dose escalation within the target, without prolonging the treatment time. It is particularly indicated for "superior sulcus" (Pancoast tumors), paravertebral and paracardiac tumors and in complex clinical situations in which conformal radiotherapy does not enable the release of non-toxic doses to organs at risk. ${ }^{24}$

IMRT significantly reduces the risk of worsening quality of life in lung cancer patients undergoing radiation therapy.

There is less toxicity with the use of IMRT compared with conformal radiotherapy for primary lung tumors, particularly regarding the rates of grade $\geq 3$ pneumonitis and requiring feeding tube.

There is also longer survival with the use of IMRT or conformal radiotherapy in relation to conventional radiotherapy, but not with IMRT compared with conventional radiotherapy.

\section{Conflict of InTERest}

The authors declare no conflict of interest.

\section{References}

1. Slotman BJ, van Tinteren H, Praag JO, Knegjens JL, El Sharouni SY, Hatton $\mathrm{M}$, et al. Use of thoracic radiotherapy for extensive stage small-cell lung cancer: a phase 3 randomised controlled trial. Lancet. 2015; 385(9962):36-42.

2. Turrisi AT 3rd, Kim K, Blum R, Sause WT, Livingston RB, Komaki R, et al. Twice-daily compared with once-daily thoracic radiotherapy in limited smallcell lung cancer treated concurrently with cisplatin and etoposide. N Engl J Med. 1999; 340(4):265-71.

3. Burdett S, Rydzewska L, Tierney J, Fisher D, Parmar MK, Arriagada R, et al.; PORT Meta-analysis Trialists Group. Postoperative radiotherapy for nonsmall cell lung cancer. Cochrane Database Syst Rev. 2005; 10:CD002142.

4. Rusch VW, Giroux DJ, Kraut MJ, Crowley J, Hazuka M, Johnson D, et al. Induction chemoradiation and surgical resection for non-small cell lung carcinomas of the superior sulcus: Initial results of Southwest Oncology Group Trial 9416 (Intergroup Trial 0160). J Thorac Cardiovasc Surg. 2001; 121(3):472-83.
5. Aupérin A, Le Péchoux C, Rolland E, Curran WJ, Furuse K, Fournel P, et al. Meta-analysis of concomitant versus sequential radiochemotherapy in locally advanced non-small-cell lung cancer. J Clin Oncol. 2010; 28(13):2181-90.

6. Almeida CE, Haddad CK, Ferrigno R. A evolução técnica da radioterapia externa. In: Sociedade Brasileira de Radioterapia. Radioterapia Baseada em Evidências. Recomendações da Sociedade Brasileira de Radioterapia. São Paulo: SBRT. Cap. 2, p. 21-6.

7. Bentzen SM, Constine LS, Deasy JO, Eisbruch A, Jackson A, Marks LB, et al. Quantitative analyses of normal tissue effects in the clinic (QUANTEC): an introduction to the scientific issues. Int J Radiat Oncol Biol Phys. 2010; 76(3 Suppl):S3-9.

8. Kong FM, Zhao J, Wang J, Finn CF. Radiation dose effect in locally advanced non-small cell lung cancer. J Thorac Dis. 2014; 6(4):336-47.

9. Sundar JK, Mullapudi N, Yao H, Spivack SD, Rahman I. Lung cancer and its association with chronic obstructive pulmonary disease: update on nexus of epigenetics. Curr Opin Pulm Med. 2011; 17(4):279-85.

10. Liu HH, Wang X, Dong L, Wu Q, Liao Z, Stevens CW, et al. Feasibility of sparing lung and other thoracic structures with intensity-modulated radiotherapy for non-small cell lung cancer. Int J Radiat Oncol Biol Phys. 2004; 58(4):1278-79.

11. Shirvani SM, Juloori A, Allen PK, Komaki R, Liao Z, Gomez D, et al. Comparison of 2 common radiation therapy techniques for definitive treatment of small cell lung cancer. Int J Radiat Oncol Biol Phys. 2013; 87(1):139-47.

12. Shirvani SM, Jiang J, Gomez DR, Chang JY, Buchholz TA, Smith B. Intensity modulated radiotherapy for stage III non-small cell lung cancer in the United States: predictors of use and association with toxicities. Lung Cancer. 2013; 82(2):252-9.

13. Chang JY. Intensity-modulated radiotherapy, not 3 dimensional conformal, is the preferred technique for treating locally advanced lung cancer. Semin Radiat Oncol. 2015; 25(2):110-6.

14. Yom SS, Liao Z, Liu HH, Tucker SL, Hu CS, Wei X, et al. Initial evaluation of treatment-related pneumonitis in advanced-stage non-small-cell lung cancer patients treated with concurrent chemotherapy and intensitymodulated radiotherapy. Int J Radiat Oncol Biol Phys. 2007; 68(1):94-102.

15. Liao ZX, Komaki RR, Thames HD Jr, Liu HH, Tucker SL, Mohan R, et al. Influence of technologic advances on outcomes in patients with unresectable locally advanced non-small-cell lung cancer receiving concomitant chemoradiotherapy. Int J Radiat Oncol Biol Phys. 2010; 76(3):775-81.

16. Graham MV, Purdy JA, Emami B, Harms W, Bosch W, Lockett MA, et al. Clinical dose-volume histogram analysis for pneumonitis after 3D treatment for non-small cell lung cancer (NSCLC). Int J Radiat Oncol Biol Phys. 1999; 45(2):323-9.

17. Hope AJ, Lindsay PE, El Naqa I, Alaly JR, Vicic M, Bradley JD, et al. Modeling radiation pneumonitis risk with clinical, dosimetric, and spatial parameters. Int J Radiat Oncol Biol Phys. 2006; 65(1):112-24.

18. Rodrigues G, Lock M, D'Souza D, Yu E, Van Dyk J. Prediction of radiation pneumonitis by dose-volume histogram parameters in lung cancer - a systematic review. Radiother Oncol. 2004; 71(2):127-38.

19. Bradley J, Graham MV, Winter K, Purdy JA, Komaki R, Roa WH, et al. Toxicity and outcome results of RTOG 9311: a phase I-II dose-escalation study using three-dimensional conformal radiotherapy in patients with inoperable nonsmall-cell lung carcinoma. Int J Radiat Oncol Biol Phys. 2005; 61(2):318-28.

20. Rose J, Rodrigues G, Yaremko B, Lock M, D'Souza D. Systematic review of dose-volume parameters in the prediction of esophagitis in thoracic radiotherapy. Radiother Oncol. 2009; 91(3):282-7.

21. Movsas B, Hu C, Sloan J, Bradley J, Kavadi VS, Narayan S, et al. Quality of Life (QOL) analysis of the Randomized Radiation (RT) dose-escalation NSCLC Trial (RTOG 0617): the rest of the story. Int J Radiat Oncol Biol Phys. 2013; 87(2):suppl, S1-2.

22. Sher DJ, Koshy M, Liptay MJ, Fidler MJ. Influence of conformal radiotherapy technique on survival after chemoradiotherapy for patients with stage III non-small cell lung cancer in the National Cancer Data Base. Cancer. 2014; 120(13):2060-8.

23. Harris JP, Murphy JD, Hanlon AL, Le QT, Loo BW Jr, Diehn M. A populationbased comparative effectiveness study of radiation therapy techniques in stage III non-small cell lung cancer. Int J Radiat Oncol Biol Phys. 2014; 88(4):872-84.

24. Ayadi M, Zahra N, Thariat J, Bouilhol G, Boissard P, Van Houtte P, Claude L, Mornex F. Radiothérapie conformationelle avec modulation d'intensité dans les carcinomes bronchiques non à petites cellules. Cancer Radiotherapie. 2014; 18(5-6):406-13. 